\title{
Therapist-Directed Protocols Designed With Health-Care Reform in Mind
}

A multitude of evidence supports the use of therapistdirected protocols in respiratory care. In 1996, Stoller ${ }^{1}$ highlighted the issue of misallocation of respiratory services and proposed therapist-driven protocols as a workable solution. His group at the Cleveland Clinic Foundation followed up with publication of data showing that therapist-driven protocols were effective in containing costs even when used on sicker subjects with longer lengths of stay. $^{2}$ At the same time, Ford and his team ${ }^{3}$ at the University of California San Diego Medical Center shared their experience with wide-scale implementation of therapist-driven protocols that resulted in a significant reduction in the amount of therapy delivered as well as a reduction in operational expenses. In 1998, Kollef and respiratory therapists ${ }^{4}$ at Barnes-Jewish Hospital enrolled almost 700 study subjects and verified that those managed through a therapist-initiated protocol received more appropriate therapy and generated fewer charges than subjects managed through physician-directed care.

\section{Therapist-Driven Protocols and Lean Hospitals}

It was in the mid-1990s that health care became interested in adopting lean methods as a way of addressing longstanding quality and cost problems. Lean methods have been used successfully in the auto industry for decades, most notably by Toyota, to reduce costs by developing processes that are more cost-efficient and require fewer resources, including capital equipment, supplies, and labor. ${ }^{5} \mathrm{~A}$ unique perspective on therapist-driven protocols that dovetailed into the lean concept was provided by Durbin $^{6}$ through his study of protocol care in the ICU at the University of Virginia. He pointed out that although therapist-driven protocols are designed for improving efficiencies in the delivery of respiratory services, they are also effective in eliminating variations in care provided to patients. By eliminating variations when providing therapy, respiratory therapists are using lean concepts to minimize the waste of over-production and under-production that occurs when patients are ordered to receive unnecessary therapy or, conversely, not treated with the appropriate therapy. In subsequent years, there have been additional investigations of therapist-driven protocols that validated the findings of these earlier studies. Therapist- driven protocols are now an accepted part of the practice of respiratory care, and few question their efficacy.

\section{Projected Growth in Health-Care Spending}

In consideration of the previous facts, one may well ask why another investigation of therapist-directed protocols is necessary or even of any interest. To find the answer, one must consider the significant transformation of health care that is under way. According to the National Health Expenditure Projections 2013-2023, overall spending on health care is estimated to increase to $19.3 \%$ of our gross domestic product by 2023, which translates into approximately $\$ 2.5$ trillion in costs per year, and hospital costs are expected to continue at a growth rate of $6.2 \%$ annually. ${ }^{7}$ Much has been made of the unsustainability of this projected rate of growth, and thus the Patient Protection and

See the Original Study on Page 151

Affordable Care Act was designed with goals aimed at ensuring health-care quality while making efforts to reduce costs. ${ }^{8}$ An amendment to the original Patient Protection and Affordable Care Act legislation established the Hospital Readmissions Reduction Program and gave the Centers for Medicare and Medicaid Services (CMS) the authority to penalize hospitals with higher than average readmission rates for a limited number of diagnosis codes by reducing overall reimbursement. CMS proposed refinements to the Readmissions Reduction Program for $2015^{9}$ and added additional diagnosis codes to the original cost containment program, including COPD. In the future, hospitals with elevated readmissions of patients with COPD will be subject to negative adjustments in their overall reimbursement rates from CMS.

\section{Therapist-Directed Protocols and Readmission Rates}

This brings us to some new information provided through the latest investigation of therapist-directed protocols. In this issue of RESPIRATORY CARE, a study by Werre et $\mathrm{al}^{10}$ provides respiratory therapists with yet another reason to implement therapist-directed protocols. The findings of their investigation suggest that a reduction in $30-\mathrm{d}$ 
readmission rates for COPD subjects with acute pneumonia may be more highly associated with care provided through therapist-directed protocols compared with physician-directed care. If these results can be validated, this piece of information will provide additional support for and justification of the value of respiratory therapists working in acute care facilities. Additionally, for respiratory therapy departments not using therapist-directed protocols, this information may provide the additional impetus needed to convince department directors, administration, and physicians to support the implementation of a protocol program.

The authors discuss limitations of their investigation that should cause respiratory therapists to view the reduced readmission data with caution. This was a retrospective study, and bias may have resulted from the process that was used to determine whether subjects were treated by therapist-directed or physician-directed care. The investigators used a listing of physicians who were known not to use the protocol as a guide to determine which subjects were assigned to the physician-directed group. Additional bias may have resulted from the unequal distribution of subjects between study groups; there were twice as many subjects in the therapist-directed group as in the physician-directed group.

The variation in readmission rates between the 2 groups is intriguing despite the noted limitations of the study. According to the CMS performance report on outcome measures, ${ }^{11}$ the median risk-standardized readmission rate for COPD exacerbations hovered around $21 \%$ in 2009 2011. The fact that the physician-directed group's readmission rates at $19.5 \%$ are consistent with existing readmission rates for patients with COPD while the therapistdirected group's readmission rates at 9.3\% are significantly below the national median supports increased reliance on the expertise of the respiratory therapist to provide timely, effective, cost-efficient care to this population of patients.

\section{Summary}

There is no doubt that therapist-directed protocols are an effective way of providing therapy to patients in need of respiratory care. Therapist-directed protocols have been shown to provide the right therapy to the right patients in an effective and efficient manner. The current investigation presents us with an additional reason for promoting the use of therapist-directed protocols by suggesting a reduced readmission rate in the therapist-directed care group. Respiratory therapists must advocate for the continued or expanded use of these therapist-driven protocols as a way of assisting their institutions to potentially reduce COPD readmissions and minimize CMS reimbursement reductions.

\section{Cheryl A Hoerr MBA/HCM RRT CPFT FAARC}

Respiratory Services Department Phelps County Regional Medical Center Rolla, Missouri

\section{REFERENCES}

1. Stoller JK. The rationale for therapist-driven protocols. Respir Care Clin N Am 1996;2(1):1-14.

2. Stoller JK, Skibinski CI, Giles DK, Kester EL, Haney DJ. Physicianordered respiratory care vs physician-ordered use of a respiratory therapy consult service: results of a prospective observational study. Chest 1996;110(2):422-429.

3. Ford RM, Phillips-Clar JE, Burns DM. Implementing therapist-driven protocols. Respir Care Clin N Am 1996;2(1):51-76.

4. Kollef MH, Shapiro SD, Clinkscale D, Cracchiolo L, Clayton D, Wilner R, Hossin L. The effect of respiratory therapist-initiated treatment protocols on patient outcomes and resource utilization. Chest 2000;117(2):467-475.

5. Graban M. Lean hospitals: improving quality, patient safety, and employee engagement, 2nd edition. Boca Raton: CRC Press; 2012: 3-4, 75.

6. Durbin CG. Therapist-driven protocols in adult intensive care unit patients. Respir Care Clin N Am 1996;2(1):105-116.

7. Centers for Medicare \& Medicaid Services. National Health Expenditure Projections 2013-2023. http://www.cms.gov/Research-Statistics-Data-and-Systems/Statistics-Trends-and-Reports/ NationalHealthExpendData/Downloads/Proj2013.pdf Accessed November 4, 2014.

8. Buntin MB, Jain SH, Blumenthal D. Patient protection and affordable care act: laying the infrastructure for national health reform. Health Affairs 2010;29(6):1214-1219.

9. Centers for Medicae \& Medicaid Services. Readmissions Reduction Program. http://www.cms.gov/Medicare/Medicare-Fee-for-ServicePayment/AcuteInpatientPPS/Readmissions-ReductionProgram.html. Accessed November 12, 2014.

10. Werre ND, Boucher EL, Beachey WD. Comparison of therapistdirected and physician-directed respiratory care in COPD subjects with acute pneumonia. Respir Care 2015;60(2):151-154.

11. Centers for Medicare \& Medicaid Services. Outcome Measures. http:// www.cms.gov/Medicare/Quality-Initiataives-Patient-AssessmentInstruments/HospitalQualityInits/OutcomeMeasures.html. Accessed November 13, 2014.

Ms Hoerr is a consultant for Southmedic and Cardinal Health.

Correspondence: Cheryl A Hoerr MBA/HCM RRT CPFT FAARC, Respiratory Services, Phelps County Regional Medical Center, 1000 West 10th Street, Rolla, MO 65401. E-mail: choerr@pcrmc.com.

DOI: $10.4187 /$ respcare. 03898 